\title{
A experiência do aborto em narrativas
}

\author{
La intemperie y lo intempestivo: \\ experiencias del aborto \\ voluntario en el relato de mujeres \\ e varones.
}

CHANETON, July; VACAREZZA, Nayla.

Buenos Aires: Marea, 2011.

Os movimentos feministas da década de 1960 e 1970 não hesitaram no uso de palavras de ordem e, possivelmente, a frase mais lembrada ainda hoje em função de ter-se tornado o grande mote da luta feminista é a famosa: 'o pessoal é político'. A expressão atribuída a um passado ainda muito presente é, de certa forma, o fio condutor do livro La intemperie y lo intempestivo: experiencias del aborto voluntario en el relato de mujeres e varones, publicado em 2011 pela editora Marea, em Buenos Aires. A obra que se dedica a reproduzir e analisar relatos de mulheres e homens que viveram a experiência do aborto clandestino na Argentina, país em que a prática é criminalizada, publiciza narrativas de pessoas que tiveram suas subjetividades e corpos marcados por um acontecimento social. A partir dessa proposta, histórias pessoais, sentimentos, subjetividades e a própria carne tornam-se políticos.

O livro é fruto de um projeto desenvolvido entre 2006 e 2009 na Universidade de Buenos Aires dirigido por July Chaneton. A responsável pelo projeto, em parceria com Nayla Vacarezza, produziu o texto que resenho. Sobre a autoria, destaco dois elementos que considerei fundamentais na construção da abordagem selecionada pelas autoras e que deu ênfase às narrativas apropriando-se da ideia do aborto como uma prática social, um acontecimento clandestino: o primeiro é a formação de July
Chaneton em Letras, o que, em minha leitura, concedeu à análise dos testemunhos uma densidade bastante interessante, na medida em que as palavras foram compreendidas em suas variedades de sentidos e significações; aliada a isso, a formação de Nayla Vacarezza em Sociologia permitiu que esses testemunhos estivessem inseridos em um sistema específico, articulados a redes de poder e de saber que, na análise, emergem como categorias relevantes. A vinculação dessas diferentes áreas de conhecimento concedeu ao livro um caráter significativamente original.

Do ponto de vista estrutural, o escrito está dividido em sete capítulos: o primeiro, "Contingência de la pasión, embarazo forzado", aborda a relação entre a gravidez indesejada e o processo de decisão; o segundo, "Cuidarse/ Sucede", foca na questão da contracepção; o terceiro, "El relato de la decisión", extrai das narrativas informações sobre o momento da decisão definitiva; o quarto, "Intervalo", descreve o caminho entre o decidir e os trâmites necessários à realização do aborto; o quinto, "Intervenciones", propõe a reflexão sobre as experiências de dor e solidão durante as intervenções, sejam cirúrgicas ou medicamentosas; o sexto, "Ellos, los participantes", analisa apenas depoimentos de homens que participaram, ou não, da experiência vivida pelas mulheres; e o sétimo e último capítulo, "Inscripto em la comunidad", elabora uma espécie de fechamento das ideias apresentadas, reivindicando uma política mais justa de liberdade para as mulheres decidirem sobre seus corpos. Nesses capítulos as autoras analisam 26 depoimentos de mulheres e homens de diferentes classes e gerações. Saliento que não pretendo elaborar um resumo das ideias apresentadas ao longo desses capítulos, mas sim destacar os pontos que considerei mais interessantes na abordagem da obra.

Partindo do questionamento "Cómo es que una pratica social pasa a convertirse en un 'problema' a debatir en el espacio público?" (p. 
18), July Chaneton e Nayla Vacarezza escapam da frieza dos números e da frequente estratégia de afirmar a questão como uma preocupação de saúde pública para demonstrar como a ilegalidade, o discurso médico, os companheiros e a sociedade civil, ou seja, um sistema androcêntrico, transformam os corpos das mulheres em um "vívido campo de poder" ( $p$. 26). Pergunta semelhante norteou o livro Práticas proibidas: práticas costumeiras de aborto e infanticídio no século $X X$, organizado por Joana Maria Pedro. ' Na obra os discursos sobre mulheres que praticaram o aborto são articulados às disputas sobre uma prática que nem sempre foi condenada e, quando o foi, foi de maneira controversa, questão que perdura ainda hoje.

Sob a égide do título que é constituído pelas palavras "intempérie" e "intempestivo", expressões muito significativas se for levado em consideração o que representa uma gravidez indesejada na vida de mulheres que não negam a maternidade, mas não se imaginam mães intempestivamente, as autoras retêm o mérito de colocarem as narrativas em evidência, mostrando o quão doloroso e complexo é todo o processo, desde a descoberta da gravidez até a recuperação nas clínicas clandestinas (no caso de mulheres de classe média) ou em hospitais públicos, no caso de complicações em função do uso do Misoprostol (no caso de mulheres pobres). A sagaz análise dos depoimentos permite a leitoras e leitores refletirem sobre a pressão exercida pela ilegalidade sobre esses corpos e subjetividades.

Assim, o que encontrei nas páginas do livro que procura contar parte da história de pessoas que passaram pela experiência do aborto em Buenos Aires é mais do que um debate que se insere indefinidamente no binômio 'contra e a favor'. É, sim, uma narrativa que, embora suas origens acadêmicas, permite a percepção de que sofrimentos, vidas e futuros estão envolvidos nesses relatos, uma boa lição para nós historiadoras, geralmente alheias ao sofrimento como possível acontecimento histórico. ${ }^{2}$

A exploração dos testemunhos, e não mais um debate 'contra versus a favor do aborto', colabora na compreensão de que o aborto não é uma prática externa à vivência de cada uma de nós, mas sim algo que é experimentado por avós, mães, primas, amigas. Assim, não é um problema de outras, e sim um problema de todas. Um dos principais méritos do livro, no entanto, não está livre de custos.

Os debates acerca do aborto nos países em que a prática não só é ilegal, como também é considerada crime, geralmente vêm acompanhados de considerações sobre estruturas religiosas e estatais, muitas vezes em parceria, que impedem outro tipo de tratamento ao tema. Embora eu considere louvável a proposta do livro, acredito que as relações de poder constitutivas e constituídas por categorias como classe e gênero que se articulam com estruturas macros, como é o caso da legislação atual na Argentina e o papel do pensamento religioso, poderiam ter recebido alguma atenção. Essa medida permitiria compreender que a ilegalidade da prática atravessa uma série de esferas até atingir mulheres que não são autorizadas a decidir sobre seus corpos e que em última análise, se apropriam desse direito por meio do aborto clandestino.

Acredito que algumas explanações contextuais não trariam prejuízo à proposta geral do livro e ajudariam leitoras e leitores a entender que tipo de estrutura está colaborando para a manutenção de uma situação que, do ponto de vista feminista, intervém diretamente na liberdade de as mulheres decidirem sobre seus corpos. Débora Diniz, estudiosa do tema no Brasil, defende que o debate não pode ser resumido a posições individuais, devendo ser compreendido no campo de luta das liberdades individuais, mas também como fundamental à saúde pública. ${ }^{3}$

A questão das categorias "gênero", "classe" e "geração" também conta a favor da obra, que, embora não tenha explorado profun-damente as questões geracionais, expressou com bastante objetividade as diferenças de experiências abortivas voluntárias em mulheres pobres e mulheres de classe média. No Capítulo 5, em que a questão é analisada com maior ênfase, visto que reflete sobre os modos de interrupção da gravidez, as autoras apontam "la hierarquizacion social articulada em torno al eje de las diferencias intragenero (entre ciudadanas mujeres). Una realidad que se oculta tras de la ilegalidad de aborto" (p. 108). É interessante notar que desde a década de 1970 o periódico Persona, ${ }^{4}$ um jornal feminista, já argumentava que as principais atingidas pela condenação do aborto como prática legal eram as mulheres pobres, na medida em que mulheres com recursos poderiam ter acesso a clínicas que, mesmo ilegais, contavam com assistência médica e pessoal qualificado. $O$ tema da interseccionalidade tem sido uma preocupação recorrente nos estudos feministas. Cito especificamente Kimberlé Crenshaw, que percebeu que o cruzamento de categorias como gênero e raça produz um tipo específico de preconceito e discriminação. ${ }^{5}$ 
O argumento das autoras é de que são as mulheres pobres as principais vítimas da legislação sobre o aborto, visto que o fazem em situações insalubres, em locais inadequados, com pessoas não preparadas, quando não o fazem sozinhas. Assim, a categoria "classe" é essencial na compreensão do aborto como uma prática que, além de estar sendo confrontada com a categoria "gênero", também o é com a noção de classe, fator que, embora não desqualifique o sofrimento psicológico e físico de mulheres com recursos materiais, aponta para o fato de que, fisicamente, mulheres pobres estão mais sujeitas a complicações decorrentes de métodos de interrupção da gravidez obtidos no mercado negro. É a importância que as autoras concedem às categorias "classe" e "gênero" que provoca grande curiosidade em relação à trajetória dessas mulheres, informações que, provavelmente, foram levantadas, mas que não puderam ser compartilhadas no livro.

Por último, destaco o elemento que ressaltei logo no começo mas sem me deter suficientemente: as autoras estão considerando o discurso da ilegalidade e tudo que deriva dele como constituidor das subjetividades dessas mulheres que se submetem à humilhação do julgamento de médicos, companheiros e da sociedade civil em geral. Eni Orlandi, em seus estudos sobre linguística, ressalta exatamente esse caráter material das palavras que, mais do que um conjunto de signos, são fundamentais na constituição de sujeitos. ${ }^{6}$ Desse modo, a fala do médico que condena uma mulher por não ter se cuidado, do companheiro que a acusa de ter engravidado propositadamente, da atendente da clínica que demonstra desprezo pelo medo da intervenção, configura-se como marcas que não abandonam a construção das subjetividades dessas mulheres que, submetidas à ilegalidade do aborto, retomam para si o direito de decidirem sobre seus corpos, decisão cujos desdobramentos são incontáveis.

O livro La intemperie y lo intempestivo: experiencias del aborto voluntario en el relato de mujeres e varones, portanto, está longe de ser um apanhado de números que comprova por meio de pesquisa científica a necessidade de legalização do aborto. O escrito de July Chaneton e Nayla Vacarezza toca no real da experiência do aborto em narrativas. Não se trata apenas de saúde pública, embora essa questão esteja em jogo. Trata-se do direito de legislar sobre os próprios corpos, corpos historicamente concebidos como femininos. Talvez seja o cenário argentino propício ao debate que permita que a obra não se detenha na frieza das estatísticas, assentindo para que essa se engaje em uma proposta feminista nítida, explorando as consequências sociais, políticas e subjetivas de uma prática que afeta diretamente um único corpo que é recorrentemente legislado por uma centena de opiniões.

\section{Notas}

1 Joana Maria PEDRO, 2003.

${ }^{2}$ Arlette FARGE, 2011

${ }^{3}$ Débora DINIZ e Marcelo MEDEIROS, 2010.

${ }^{4}$ Persona foi uma revista feminista que circulou na Argentina em momentos distintos e com periodicidades diferentes. Com edições mensais a partir de outubro de 1974, que mais tarde perderam a periodicidade, foi publicada até meados da década de 1980. A publicação fol editada pelo grupo Movimiento de Liberación Femenina (MLF), cuja líder era María Elena Oddone. Em 1973, o grupo inaugurou um escritório, formou uma biblioteca, organizou conferências e debates sobre temas feministas e iniciou contato com importante grupo do período, a Unión Feminista Argentina (UFA).

${ }^{5}$ Kimberlé CRENSHAW, 2002.

${ }^{\circ}$ Eni P. ORLANDI, 2009.

\section{Referências}

CRENSHAW, Kimberlé. "Documento para o encontro de especialistas em aspectos da discriminação racial relativos ao gênero". Revista Estudos Feministas, v. 10, n. 1, p. 171 188, 2002.

DINIZ, Débora; MEDEIROS, Marcelo. "Aborto no Brasil: uma pesquisa domiciliar com técnica de urna". Ciência \& Saúde Coletiva, v. 15, p. 959-966, 2010. (Suplemento 1). Disponível em: $<\mathrm{http}$ ://www.scielo.br/pdf/csc/v15s1/ 002.pdf>. Acesso em: 20 jul. 2012.

FARGE, Arlette. Lugares para a história. Belo Horizonte: Autêntica, 2011.

ORLANDI, Eni P. Análise de discurso: princípios e procedimentos. Campinas, SP: Pontes, 2009.

PEDRO, Joana Maria (Org.). Práticas proibidas: práticas costumeiras de aborto e infanticídio no século XX. Florianópolis: Cidade Futura, 2003.

Cíntia Lima Crescêncio

Universidade Federal de Santa Catarina 